\title{
A distinção entre princípios e regras como espécies de normas na obra teoria dos direitos fundamentais de Robert Alexy ${ }^{1}$
}

\author{
The distintion between principles and rules as species of standards in the work theory of \\ fundamental rights from Robert Alexy
}

Rogério Cangussu Dantas Cachichi ${ }^{2}$

\section{Resumo}

0 presente artigo reconstrói a distinção entre regras e princípios como espécies de normas na obra Teoria dos direitos fundamentais do filósofo do direito Robert Alexy. Dá ênfase à distinção sob 0 aspecto da antinomia normativa, com aplicação do pensamento de Alexy na resolução de conflito de regras e colisão de princípios em hipóteses concretas.

Palavras Chave: Filosofia do direito; Princípios; Regras; Colisão; Robert Alexy.

\begin{abstract}
This article recreate the distinction between rules and principles as standards in the work Theory of the Fundamental Rights from philosopher Robert Alexy. It emphasizes the distinction by the aspect of normative contradiction, applying the thinking of Alexy in conflict resolution of rules and principles and the collision of principles in specific circumstances.
\end{abstract}

Keywords: Philosophy of law, Principles, Rules, Collision, Robert Alexy.

\section{Introdução}

A Teoria dos direitos fundamentais do filósofo do direito Robert Alexy, publicada no ano de 1985, à evidência, trata com larga amplitude e profundidade de muitos outros problemas, especialmente ligados à exegese dos direitos fundamentais, não focados, sequer mencionados, neste trabalho. Alexy $(2008$, p. 38) na obra citada logrou alinhavar uma teoria

\footnotetext{
${ }^{1}$ Artigo oriundo de trabalho acadêmico apresentado na disciplina Prática de Pesquisa em Filosofia II do Curso de Licenciatura em Filosofia da Universidade Estadual de Londrina. Orientador: Prof. Antônio Tadeu Bairros. Co-orientador: Prof. Elve Miguel Cenci. Dedicado a Henrique Castelo Perez.

${ }^{2}$ Graduado em Direito pela Faculdade de Direito de São Bernardo do Campo (1992-1996). Especialista em Direito Tributário pela Pontifícia Universidade Católica de São Paulo - PUC/SP (1999-2000). Aluno do 2o ano de Filosofia na Universidade Estadual de Londrina - UEL(2008). Juiz Federal Substituto da $2^{2}$ Vara Federal em Londrina.
} 
jurídica geral dos direitos fundamentais da Constituição alemã. Em outras palavras, “...uma teoria que se ocupa com problemas relacionados a todos os direitos fundamentais [dessa Constituição]...". Este trabalho tão-somente reconstruirá a distinção entre regras e princípios como espécies de normas bem esboçada na primeira metade do capítulo terceiro da obra, que cuida da estrutura das normas de direitos fundamentais ${ }^{3}$.

Há algum consenso ${ }^{4}$ de que a elaboração teórica de Ronald Dworkin foi a primeira que frisou com mais nítidos contornos essa distinção entre princípios e regras. Fê-lo opondose ao positivismo jurídico, especialmente da versão do jurista Herbert Hart. Consignou textualmente Dworkin: "Quero lançar um ataque geral contra o positivismo e usarei a versão de H.L.A.Hart como alvo, quando um alvo específico se fizer necessário" (DWORKIN, 2002, p.35). De sua feita, "Alexy, partindo das considerações de Dworkin, precisou ainda mais o conceito de princípios" (apud ÁVILA, 2007, p.37), assertiva esta que Sobrevilla (1996, p. 97) confirmou:

Robert Alexy propôs de início um modelo jurídico de regras e princípios em seu artigo 'Zum Begriff des Rechtsprinczips', no qual comentava e criticava a distinção entre regras e princípios de Ronald Dworkin e, por sua vez, tomava-a como ponto de partida para sua própria teoria. Desenvolveu o modelo jurídico de regras e princípios em seu livro Theorie der Grundrechte, que foi seu trabalho de habilitação ${ }^{5}$

Para consecução dos fins deste texto, depois da focagem do tema dentro da dogmática jurídica e da demonstração de sua importância na construção da teoria dos direitos fundamentais, passar-se-á ao cotejo das espécies normativas (princípios e regras), mas não sem antes expor a noção do gênero (norma) ao qual elas pertencem. Na seqüência, evidenciar-se-á como a análise da contradição entre normas reforça a distinção entre regras e princípios. 0 texto chega a termo com a apresentação dos desdobramentos da aplicação da distinção nos exemplos citados na obra de Alexy.

\footnotetext{
${ }^{3}$ Para uma visão global do modelo jurídico proposto por Alexy, claro, afigura-se-nos indispensável a cabal leitura da obra. Tivemos acesso a duas traduções muito boas, uma espanhola, outra brasileira, ambas indicadas ao final nas referências bibliográficas.

${ }_{5}^{4}$ Nesse sentido: Ávila, 2007, p.36; Sobrevilla, 1996, p.97; Cf. o próprio Alexy, 1988, p.139.

5 "A Teoria dos Direitos Fundamentais de Robert Alexy, publicado em 1985, foi o trabalho apresentado para sua habilitação na Faculdade de Direito da Universidade Georg August em Gotinga" (Amorim, 2005, p.124). Neste trabalho, a tradução de citações dos textos em espanhol é de nossa responsabilidade.
} 


\section{A distinção entre princípios e regras como espécies de normas na obra teoria dos direitos fundamentais de Robert Alexy}

\section{Relevância da distinção na construção da teoria dos direitos fundamentais de Robert Alexy}

Problemas como a identificação de quais seriam os direitos fundamentais, os princípios a nortear a legislação e as exigências da realização da dignidade humana, da liberdade e da igualdade (ALEXY, 2008, p.25), uma vez positivados na Constituição alemã, passaram ao âmbito da dogmática jurídica. ${ }^{6}$ Dogmática essa que comporta três dimensões: analítica, empírica e normativa. Grosso modo, a empírica cuida de validez e eficácia da norma positivada; a normativa da reflexão crítica da práxis jurídica ${ }^{7}$. No entanto é a dimensão analítica que objetiva dissecar sistemática e conceitualmente o direito vigente. Alexy (2008, p. 38) explica:

Clareza conceitual, ausência de contradição e coerência são pressupostos da racionalidade de todas as ciências. Os inúmeros problemas sistemático-conceituais dos direitos fundamentais demonstram o importante papel da dimensão analítica no âmbito de uma ciência prática dos direitos fundamentais que pretenda cumprir sua tarefa de maneira racional.

Eis aí o cerne analítico-estrutural no qual se embute a distinção entre princípios e regras como espécies de norma de direito fundamental. Analítico na medida em que se busca limpidez e precisão conceitual, condição mínima de racionalidade em ciência. "Na filosofia do direito, a dimensão analítica se refere a conceitos como os de norma, 'dever ser', pessoa, ação, sanção e instituição" (ALEXY, 2003, p.149). Estrutural, porque tal limpidez e precisão purifica conceitos de elementos constitutivos - estruturais, portanto - no âmbito dos direitos fundamentais.

Ora, tanto a formulação de juízos que se pretendam racionalmente fundamentados como crítica intersubjetiva desses mesmos juízos “...pressupõe clareza tanto acerca da estrutura das normas de direitos fundamentais quanto acerca de todos os conceitos e formas argumentativas relevantes para a fundamentação no âmbito dos direitos fundamentais" (ALEXY, 2008, p.43). Deveras, "se não há clareza acerca da estrutura dos

\footnotetext{
${ }^{6}$ "O que faz uma teoria ser dogmática e, em decorrência disso, jurídica é algo pouco claro. É natural orientarse, de início, por aquilo que de fato é praticado como Ciência do Direito e designado como 'dogmática jurídica' ou 'ciência jurídica', ou seja, pela Ciência do Direito em sentido estrito e próprio" (Alexy, 2008, p.33).

${ }^{7}$ Para maior detalhamento a respeito das dimensões da dogmática, especialmente da empírica e da normativa, cf. Alexy, 2008, p.34 e ss.
} 
direitos fundamentais e de suas normas, não é possível haver clareza na fundamentação nesse âmbito" (ALEXY, 2008, p.45).

Assim, o autor, na obra em estudo, depois da análise do conceito de norma de direito fundamental no capítulo segundo, passará no capítulo seguinte a perscrutar-lhe a estrutura, ao ensejo da qual cai a lanço a distinção entre princípios e regras sob o gênero daquela norma. A propósito da importância da distinção, o mesmo Alexy (2008, p. 85) dilucida:

Para a teoria dos direitos fundamentais, a mais importante delas é a distinção entre regras e princípios. Essa distinção é a base da teoria da fundamentação no âmbito dos direitos fundamentais e uma chave para a solução de problemas centrais da dogmática dos direitos fundamentais. (...)Nesse sentido, a distinção entre regras e princípios é uma das colunas-mestras do edifício da teoria dos direitos fundamentais.

Demonstrada a necessidade de precisão conceitual, principalmente em relação às entidades pelas quais o direito é estruturado, a seguir serão expostos, ainda que sinteticamente, os nucleares pontos do conceito de norma e das espécies regras e princípios.

\section{Norma como gênero de que são espécies regras e princípios}

Antes da delimitação das espécies, convém o exame do gênero. Porém, é de bom aviso advertir que o próprio conceito de norma, definição das mais abstratas e importantes da filosofia do direito (ALEXY, 2003, p.154), gera muita polêmica, pois toca em ponto fundamental da Ciência do Direito, pressupondo decisões a respeito de seu objeto, método, enfim, de seu caráter (ALEXY, 2008, p.52).

A par da divergência, norma de direito fundamental, semanticamente considerada ${ }^{8}$ tal como concebida por Alexy, constitui o significado extraído de determinado enunciado normativo segundo três modais deônticos, quais sejam: é obrigatório (modalidade deôntica da obrigação ou do dever), é proibido (modalidade deôntica da proibição) ou é permitido (modalidade deôntica permissão). ${ }^{9}$ Factível, ainda, 0 seguinte cotejo: 0 enunciado proposicional está para o enunciado normativo assim como a proposição está para a norma;

\footnotetext{
${ }^{8}$ Alexy fundamenta-se no conceito semântico de norma, lastreado no significado (norma) extraído do enunciado normativo (texto legal). A respeito da polêmica e da exposição do conceito, cf. 2008, p.52 e ss.

${ }^{9}$ Para um excel ente aprofundamento acerca das modalidades deônticas básicas, cf. Alexy, 2008, p.204 e ss.
} 


\section{A distinção entre princípios e regras como espécies de normas na obra teoria dos direitos fundamentais de Robert Alexy}

ou, como destacou Alexy, "a relação entre enunciado normativo e norma equivale à relação entre enunciado afirmativo e afirmação" (ALEXY, 2008, p.57) ${ }^{10}$.

Ademais, normas de direito fundamental são os significados extraídos, diretamente ou não ${ }^{11}$, de enunciados normativos constantes da parte de direitos fundamentais das Constituições - e, na perspectiva concreta da Teoria dos direitos fundamentais de Alexy, da Constituição alemã (ALEXY, 2008, p.65).

Vale dizer, outrossim, que uma única norma pode ser extraída de enunciados normativos diferentes: a proibição de penas cruéis, por exemplo, é norma de direito fundamental na atual Constituição brasileira no art.5o, XLVII, "e" do Texto Constitucional: "não haverá penas: ...e)cruéis" ${ }^{12}$, porém a mesma norma poderia ser expressa de outras formas como "não se admite pena cruel"(i), "não será cominada pena cruel" (ii), "são inadmissíveis penas cruéis" (iii); "ninguém será submetido a penas cruéis" (iv); "nenhuma pena será cruel" (v) e assim avante (ALEXY, 2008, p. 204).

Espécies de norma são princípios e regras. Estas são normas com a mesma estrutura deôntica que devem ser cumpridas. Princípios, por sua vez, são normas a serem cumpridas na maior medida possível dentro de possibilidades jurídicas e reais existentes (ALEXY, 2008, p.90). O próprio autor, noutra obra, expõe com cirúrgica precisão:

Há portanto distintos graus de cumprimento. Se se exige a maior medida possível de cumprimento em relação com as possibilidade jurídicas e fáticas, se trata de um princípio. Se tão-somente se exige uma determinada medida de cumprimento, se trata de uma regra (ALEXY, 1988, p.144)

Destarte, verbere-se que, na condição de normas, tanto princípios como regras no âmbito deôntico estatuem o dever-ser que ordena, proíbe ou permite. Porém a norma-regra é cumprida quando, ocorrido no mundo fenomênico o fato por ela previsto, tem-se também a conseqüência jurídica decorrente; descumprida em caso contrário. Note-se que a aplicação

\footnotetext{
${ }^{10} 0$ próprio Alexy, contudo, adverte linhas depois que a relação entre enunciado afirmativo e afirmação estabelece-se no campo ontológico, do ser; ao passo que a conexão entre enunciado normativo e norma no deôntico, do dever-ser (cf. 2008, p.58).

${ }^{11}$ As normas de direito fundamental não extraídas diretamente de enunciados normativos da Constituição foram denominadas por Alexy normas atribuídas: "As normas de direito fundamental podem, portanto, ser divididas em dois grupos: as normas de direito fundamental estabelecidas diretamente pelo texto constitucional e as normas de direito fundamental atribuídas" (2008, p.73).

${ }^{12}$ Alexy exemplifica por meio da norma que proíbe a extradição de alemães, cf. 2008, p.54-55.
} 
da regra exclui considerações outras não autorizadas, diversamente dos princípios.

o mandamento de princípio realiza-se, como se pressente, tomando em consideração elementos não previstos: limites fáticos (possibilidades reais existentes) e jurídicos (possibilidades jurídicas existentes); este segundo "determinado pelos princípios e regras colidentes" (ALEXY, 2008, p.90). Justamente em função disso a norma-princípio admite diferentes medidas de cumprimento conforme mencionadas possibilidades. Princípios como o da liberdade, da igualdade, do direito à saúde e outros encontram delimitação não só na realidade social e econômica, como também na jurídica.

Por isso, diversamente das regras, princípios constituem mandamentos de otimização (ALEXY, 2008, p.90). Com tal expressão Alexy quer significar exatamente que 0 cumprimento dos princípios, diferente do das regras, pode se dar em diferentes graus e depende não só das circunstâncias fáticas, mas também jurídicas.

Esse cerne da diferença, como se vê, denuncia a importância do estudo das contradições entre normas como fator de delimitação entre suas espécies. "A diferença entre regras e princípios mostra-se com maior clareza nos casos de colisões entre princípios e de conflitos entre regras" (ALEXY, 2008, p.91). Pode-se dizer, pois, que a colisão de princípios e o conflito de regras são instrumentos dos quais pode o intérprete lançar mão ao fazer a distinção entre princípios e regras. É o que doravante veremos.

\section{Contradição normativa como critério de distinção}

Alexy denomina colisão a contradição entre normas da espécie princípio e conflito a contradição entre normas da espécie regra. Para ele:

Comum às colisões entre princípios e aos conflitos entre regras é o fato de que duas normas, se isoladamente aplicadas, levariam a resultados inconciliáveis entre si, ou seja, a dois juízos concretos de dever-ser jurídico contraditórios. E elas se distinguem pela forma de solução do conflito (ALEXY, 2008, p.91).

Sendo assim, diga-se sem mais delongas que o conflito de regras é solvido por uma de duas técnicas, a saber: instituição de uma das regras conflitantes como cláusula de exceção à outra ou, não sendo isso possível, declarando uma delas inválida (ALEXY, 2008, p.92).

De sua parte, a colisão de princípios é solucionada de diverso modo. Na condição de 


\section{A distinção entre princípios e regras como espécies de normas na obra teoria dos direitos fundamentais de Robert Alexy}

mandamentos de otimização, sem que haja invalidade de qualquer um deles, um dos princípios cede em relação a outro na precisa medida exigida pelas circunstâncias do caso concreto em que a colisão sucedeu. Noutras palavras, as nuances do caso concreto determinarão qual o princípio detém menos peso ${ }^{13}$, a ceder em favor do de maior peso (ALEXY, 2008, p.93). ${ }^{14}$

Por derradeiro, insta apresentar, à guisa de ilustração, alguns modelos, mesmo poucos mas concedidos pelo próprio Alexy, nos quais fiquem patenteados, em dimensão mais palpável, os desdobramentos da aplicação e uso da distinção cá tratada. Objetiva-se, assim, tornar mais clara a exposição do assunto e, por consectário, menos árdua a compreensão do até então alinhavado.

Com efeito, exemplo de conflito de regra é “...aquele entre a proibição de sair da sala de aula antes que o sinal toque e o dever de deixar a sala se soar o alarme de incêndio" (ALEXY, 2008, p.92). Nessa hipótese, o conflito é resolvido ao reputar a segunda norma como cláusula de exceção da primeira, de tal arte que, dado o alarme de incêndio, mesmo que não finda a aula, deve-se sair da sala de aula. Lado outro, impossível que seja reconhecer uma das regras em conflito como cláusulas de exceção, então “...pelo menos uma das regras tem que ser declarada inválida e, com isso, extirpada do ordenamento jurídico" (ALEXY, 2008, p.92), como o conflito entre a lei federal que, visando a regulamentação do horário de trabalho, permitia o funcionamento até $19 \mathrm{~h}$ das lojas em dias úteis e a lei estadual que lhes vedava o funcionamento às quartas depois das $13 \mathrm{~h}$. 0 Tribunal alemão reputou inválida a lei estadual. "As duas regras não poderiam valer ao mesmo tempo, caso contrário a abertura das lojas nas tardes de quarta-feira seria tanto permitida quanto proibida" (ALEXY, 2008, p.93).

A hipótese de colisão de princípios, de outra parte, foi ilustrada por Alexy a partir de

\footnotetext{
${ }^{13}$ Vale-se da metáfora do peso para transmitir a idéia de precedência, de primazia de um princípio em relação ao outro. Sobre o emprego da difundida metáfora do peso pelo Tribunal alemão, cf. Alexy, 2008, p.97.

${ }^{14}$ É claro que o discurso jurídico, dentro do qual se estabelecerão essas circunstâncias, bem como a atuação de cada uma delas sobre um ou outro princípio, há de ser fundamentado por meio da argumentação racional, objeto da teoria da argumentação jurídica, mas da qual não se cuidará aqui. Conquanto não seja objeto do trabalho, Alexy sintetizou: "Os níveis da regra e dos princípios devem certamente complementar-se com um terceiro, a saber, com uma teoria da argumentação jurídica, que diz como, sobre a base de ambos os níveis, é possível uma decisão racionalmente fundamentada" (Alexy, 1988, p.149). Vale consignar que Robert Alexy tratou com minúcias da mencionada teoria da argumentação jurídica em obra com esse título, traduzida para o português por Zilda Hutchinson Schild Silva e publicada em 2001 pela Landy editora, a que remetemos 0 leitor.
} 
dois precedentes do Tribunal Constitucional Federal alemão, a saber, a decisão sobre a incapacidade de participar de audiência processual e a decisão no caso Lebach. Alexy expõe os motivos da seleção desses dois modelos:

A análise da primeira decisão servirá para a compreensão da estrutura das soluções de colisões, que será resumida em uma lei de colisão; e a análise da segunda, para aprofundar essa compreensão e conduzir a uma concepção do resultado do sopesamento ${ }^{15}$ como norma de direito fundamental atribuída. (ALEXY, 2008, p.94).

Como o aprofundamento do estudo a respeito da colisão de princípios não é o escopo direto do presente trabalho, aqui nos ateremos apenas ao primeiro caso, para compreensão e solução do qual se deve ter presente que princípios opostos serão reciprocamente considerados, isto é, um em relação ao outro à vista das peculiaridades da hipótese sob julgamento. Até porque, a se entender de outro modo, isto é, em si (ou isoladamente) considerados, princípios não seriam mandamentos de otimização, senão de maximização e nessa última perspectiva desprezar-se-iam princípios opostos, a se inviabilizar alguma colisão ${ }^{16}$.

Impende frisar, ainda, que a ponderação (ou sopesamento) entre princípios colidentes estabelece-se sempre no âmbito concreto, vale redizer: as nuances da causa é que determinarão os critérios pelos quais se concluirá que um princípio possui maior peso que outro. 0 conjunto desses critérios e o resultado da ponderação formará o que chamou Alexy de lei da colisão, que estipula as circunstâncias concretas segundo as quais um princípio ostenta prevalência em relação a outro. A lei da colisão expressa a relação concreta e condicionada de precedência:

No caso da incapacidade processual, dois princípios colidiram: de um lado, a aplicação da lei penal $\left(\mathbf{P}_{\mathbf{1}}\right)$; de outro, o direito à vida e à integridade física do acusado $\left(\mathbf{P}_{\mathbf{2}}\right)$. Discutia-se acerca da obrigatoriedade ou não de estar presente em audiência processual certo acusado, enfermo a tal ponto que sua simples participação neste ato seria apta a Ihe gerar risco de derrame cerebral ou de infarto. Isoladamente considerados, ambos os

\footnotetext{
${ }^{15}$ Ou "ponderación" como traduziu a edição espanhola da obra (Cf. na trad. espanhola, Alexy, 2007, p.71).

${ }^{16}$ Registra Alexy em nota: "Se se deixa de lado um dos princípios colidentes, a referências às possibilidades jurídicas perde seu significado. De mandamento de otimização, o princípio seria transformado em mandamento de maximização relativo apenas às possibilidades fáticas. Isso conduz à idéia geral segundo a qual os princípios, se isoladamente considerados - isto é, independentemente de sua relação com outros princípios -, têm natureza de mandamentos de maximização" (2008, p.95, nota 37).
} 


\section{A distinção entre princípios e regras como espécies de normas na obra teoria dos direitos fundamentais de Robert Alexy}

princípios conduziriam a juízos contraditórios: $\mathbf{P}_{\mathbf{1}}$ determina a realização da audiência; $\mathbf{P}_{\mathbf{2}}$, por seu turno, a proíbe.

O Tribunal Constitucional Federal alemão, então, tomou o risco concreto de perecimento da vida e a possibilidade de grave dano à saúde do acusado como condições $\left(\mathbf{C}_{1}, \mathbf{C}_{\mathbf{2}}\right)$ para determinar, no caso sob julgamento, a precedência de $\mathbf{P}_{\mathbf{2}}$ em relação à $\mathbf{P}_{\mathbf{1}}$, logo restou proibida a realização audiência com a participação do acusado. Esse o resultado da ponderação (ou sopesamento) entre os princípios $\mathbf{P}_{\mathbf{1}}$ e $\mathbf{P}_{\mathbf{2}}$, em vista das circunstâncias $\mathbf{C}_{\mathbf{1}}, \mathbf{C}_{\mathbf{2}}$.

Como se denota, a solução da colisão pode ser formalizada por meio da seguinte lei: dadas as condições $\mathbf{C}_{\mathbf{1}}, \mathbf{C}_{\mathbf{2}}$ (suporte fático da lei da colisão), então $\mathbf{P}_{\mathbf{2}}$ tem precedência em relação à $\mathbf{P}_{\mathbf{1}}$ (conseqüência jurídica $\mathbf{R}$ ). "As condições sob as quais um princípio tem precedência em face de outro constituem o suporte fático de uma regra que expressa a conseqüência jurídica do princípio que tem precedência" (ALEXY, 2008, p.99). Em notação, a Lei da colisão seria $\mathbf{C} \rightarrow \mathbf{R}$, que equivale a $\left\{\mathbf{C}\left(\mathbf{C}_{\mathbf{1}} \& \mathbf{C}_{2}\right) \rightarrow \mathbf{R}\left(\mathbf{P}_{\mathbf{2}} \mathbf{P} \mathbf{P}_{\mathbf{1}}\right)\right\}$, onde \& representa a conjunção das duas condições da relação de precedência $\mathbf{C}_{1}, \mathbf{C}_{2}, \rightarrow 0$ operador lógico da implicação (se...então) e $\mathbf{P}$ a própria relação de precedência.

À vista disso, pode-se perceber como a distinção entre princípios e regras é reforçada pela aplicação dos dois modos de resolução de contradição entre normas. Com efeito, pode-se dizer que princípios são normas cuja contradição é superada por ponderação orientada pela lei de colisão (colisão de princípios) e regras aquelas das quais a contradição é revolvida a partir da criação de regras de exceção ou invalidez de uma das normas conflitantes (conflito de regras).

\section{Conclusões}

Do quanto restou escrito, cabe-nos, antes de pôr cobro à tarefa a que nos propusemos, apresentar em forma de enxuto rol este elenco de principais conclusões:

Robert Alexy em sua Teoria dos direitos fundamentais, ao ensejo de expor uma teoria jurídica geral dos direitos fundamentais na Constituição alemã, apresentou a distinção estudada entre princípios e regras.

1. Positivados, à Ciência do Direito (dogmática jurídica) cabe o exame dos direitos fundamentais sob três dimensões: analítica, empírica e normativa, das quais na 
primeira tem-se a depuração da terminologia, dos conceitos estruturais, enfim, da linguagem, sem a qual precisão nenhuma ciência pode edificar-se.

2. Norma, sob o prisma semântico, é significado; significado extraído de enunciados normativos de estrutura deôntica modalizada por dever, por proibição, por permissão.

3. Regra é norma que deve ser cumprida.

4. Princípio é norma que deve ser cumprida na maior medida possível dentro das possibilidades jurídicas e reais existentes; portanto, mandamento de otimização.

5. Conflito de regras e colisão de princípios, fenômenos da antinomia normativa, auxiliam na delimitação entre as espécies de normas.

6. O conflito de regras resolve-se ou pela cláusula de exceção ou pela invalidação de uma das normas conflitantes.

7. A colisão de princípios, que pressupõe a tomada dos princípios opostos em situação de reciprocidade, opera-se no caso concreto por meio da lei da colisão que exprime a relação condicionada de precedência de um em relação ao outro princípio.

Ao cabo, as dificuldades inerentes ao tema decorrem de seu viés altamente abstrato. Alexy reconhecia que o conceito de norma é dos mais abstratos da filosofia do direito, abstração esta que se estende também em relação a conceitos diretamente inferidos como tipos de normas (princípios e regras) e mecanismos para superação de contradição entre elas (conflito de regras e colisão de princípios) ${ }^{17}$. De qualquer modo, é intuitivo que a clara percepção de tais conceitos filosóficos fundamentais assume capital importância não apenas para a Teoria dos direitos fundamentais de Robert Alexy, mas também para qualquer teoria geral das normas, teoria do ordenamento jurídico e na compreensão da conexão entre direito e moral e até da própria natureza do direito.

17 “Em todo o caso, o conceito de norma ou de 'dever ser' é ao menos um candidato para ser o conceito mais abstrato da filosofia do direito. Se se descende um passo deste nível de abstração, o impacto inferencial dos conceitos fundamentais do direito chaga a ser muito mais que óbvio. A distinção entre regras e princípio é um assunto altamente abstrato de teoria geral das normas. Ao mesmo tempo, tem consequências de largo alcance para a teoria do ordenamento jurídico. Se o direito contem os dois tipos de normas, então 0 ordenamento jurídico inevitavelmente combinará a subsunção com a ponderação. Como conseqüência, o ordenamento jurídico estará determinado por estruturas que são as mesmas do ordenamento prático geral. Esta é uma importante razão para não conceber o ordenamento jurídico como um âmbito com direito próprio, separado e distinto de outros âmbitos da razão.

Todo isto mostra que as perguntas filosóficas fundamentais deve ser respondidas a fim de compreender a natureza do direito. A reflexão sobre a natureza do direito não pode ter êxito se é separada da filosofia geral." (Alexy, 2003, p.154). 


\section{A distinção entre princípios e regras como espécies de normas na obra teoria dos direitos fundamentais de Robert Alexy}

\section{Referências}

ALEXY, Robert. La naturaleza de la filosofía del derecho. Doxa, Barcelona, n.26, 2003. Disponível em: «ttp://descargas.cervantesvirtual.com/servlet/SirveObras/ 791266200076 83940700080/015782.pdf? incr=1 $>$. Acesso em: 12 jul.2009.

. Sistema jurídico, principios jurídicos y razón práctica. Doxa, Barcelona, n.5, 1988.

Disponível em: ঝttp://www.cervantesvirtual.com/servlet/SirveObras/ 12471730982570739 687891/cuaderno5/Doxa5_07.pdf>. Acesso em: 12 jul.2009.

Landy, 2001.

. Teoria da argumentação jurídica. Tradução Zilda Hutchinson Schild Silva. São Paulo:

. Teoria dos direitos fundamentais. Tradução de Virgílio Afonso da Silva. São Paulo:

M alheiros, 2008. [trad. esp. Teoría de los derechos fundamentales. 2ª̣ed. Tradução de Carlos Bernal Pulido. Madri: Centro de Estudios Politicos y Constitucionales, 2007.

AM ORIM, Letícia Balsamão. A distinção entre regras e princípios segundo Robert Alexy: esboço e críticas. Revista de Informação Legislativa, Brasília, n.165, jan./mar. 2005.

Disponível em <http:// www.senado.gov.br/web/cegraf/ril/Pdf/pdf_165/R165-11.pdf>. Acesso em: 12 jul.2009.

ÁVILA, Humberto. Teoria dos princípios: da definição à aplicação dos princípios jurídicos. 7a.ed. São Paulo: Malheiros, 2007.

DW ORKIN, Ronald. Levando a sério os direitos. Tradução de Nelson Boeira. São Paulo: M artins Fontes, 2002.

PEDRON, Flávio Quinaud. Comentários sobre as interpretações de Alexy e Dworkin. Revista CEJ, n.30, jul./set. 2005. Disponível em: বhttp:// www2.cjf.jus.br/ojs2/ index.php/cej/article/view/680/860>. Acesso em: 12 jul.2009.

SOBREVILLA, David. El modelo jurídico de reglas, principios y procedimientos de Robert Alexy. Isonomía, n.4, abril/1996. Disponível em বttp:// www.cervantesvirtual.com/servlet/SirveObras/doxa/01474063322636384254480/is onomia04/iso09.pdf $>$. Acesso em: 12 jul.2009. 